\title{
Hideyo Noguchi (1876-1928): Distinguished bacteriologist
}

\author{
Siang Yong $\operatorname{Tan}^{1}, \mathrm{MD}, \mathrm{JD}$, Jill Furubayashi ${ }^{2}$
}

$\mathrm{H}$ ideyo Noguchi overcame significant adversity to become a physician-scientist - a humble origin and a crippling childhood injury render his achievements all the more extraordinary. In typical fashion, Noguchi attributed his success to pure diligence, saying, "There is no such thing as genius [...] to work three, four, five times harder than anyone else, that is genius."

EARLY CAREER Born Seisaku Noguchi on November 24, 1876, to impoverished, illiterate farmers in Inawashiro, Fukushima prefecture, Japan, Noguchi as toddler fell into a hearth, sustaining burns to the left side of his body that left him with a permanently disfigured hand with fused fingers. However, this disability did not detract from Noguchi's enthusiasm and hard work, catching the attention of a school principal, Sakae Kobayashi, who recommended a transfer to a better school. At age 16, Noguchi travelled to Wakamatsu, a neighbouring town, where he underwent reconstructive hand surgery by Dr Kanae Watanabe. This experience exposed young Noguchi to medicine and sparked his interest in science, eventually inspiring him to become a physician.

Noguchi next moved to Tokyo, working as a janitor while studying, and in 1896 took and passed the first half of the medical practitioner's exam. The following year, at age 21, he graduated from Tokyo Medical College, Tokyo, Japan, and upon obtaining his doctor's license, took on a lectureship.

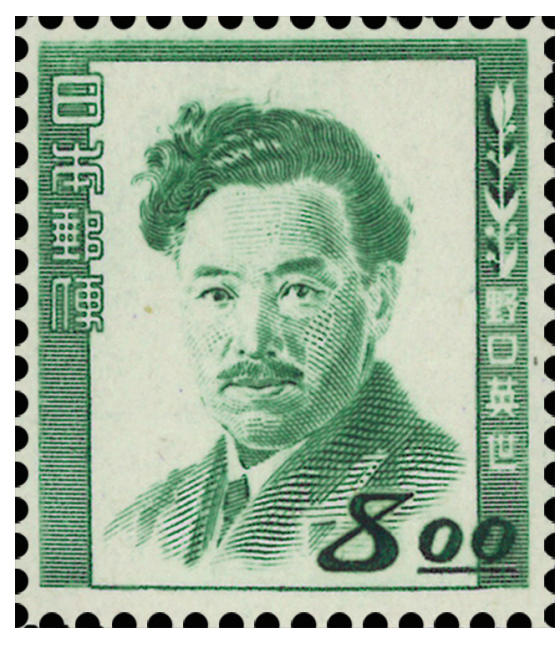

won a fellowship to study with Thorvald Madsen in Copenhagen, and upon his return a year later, joined the newly established Rockefeller Institute for Medical Research (RIMR). It turned out that its director was Flexner, his old mentor, and it was there that Noguchi launched his career in infectious disease research.

SYPHILIS In 1909, Noguchi published an extensive monograph, Snake Venoms: An Investigation of Venomous Snakes with Special Reference to the Phenomena of Their Venoms, which established his reputation as a serious and productive scientist and secured his position at RIMR. There he stayed for the rest of his career, publishing over 200 papers on a range of infectious diseases as diverse as syphilis, tuberculosis, trachoma, poliomyelitis, rabies, verruga peruviana, yellow fever, Rocky Mountain spotted fever and Oroya fever.

Following the 1905 discovery of Treponema pallidum (T. pallidum), the causative organism of syphilis, by German scientist Fritz Schaudinn, Noguchi developed an improved diagnostic method (using complement fixation analysis) and a luetin skin test for syphilis. In 1913, Noguchi successfully isolated T. pallidum from the brains of patients with general paresis and tabes dorsalis, thus establishing the aetiology of neurosyphilis. Flexner was one of the first to be notified of this discovery, and helped to confirm that several of the slides from patients with neurosyphilis did in fact feature the spirochaete.

In 1910, Noguchi published a popular There, he met his to-be lifelong friend and mentor, Dr Morinosuke Chiwaki. Noguchi initially had a difficult time finding work as a clinician because of his deformity. During this time, he discarded his given name of Seisaku after reading a fictional story about a lazy, failed physician by that name, and instead chose to rename himself 'Hideyo', which means 'superior man of the world'.

ROCKEFELLER INSTITUTE In 1899, Noguchi met Dr Simon Flexner, a physician and researcher at the University of Pennsylvania, Philadelphia, Pennsylvania, United States, who had stopped in Tokyo on his way to the Philippines. His friendship with Flexner proved to be a life-changing event. In 1901, an eager Noguchi left for Philadelphia, where he was able to land a position at the University of Pennsylvania's Department of Pathology. Noguchi's early research was on the physiologic effects of snake venom, such as haemolysis, haemorrhage, oedema and endothelial damage. After three years, Noguchi book on syphilis, Serum Diagnosis of Syphilis, and his findings and sketches on syphilis were subsequently reproduced in Jordan and Falk's Newer Knowledge of Bacteriology in 1928. Despite his halting English, Noguchi lectured widely before European scientists in Frankfurt, Berlin, Copenhagen, Stockholm, and London. His work in bacteriology earned him international acclaim and accolades, winning recognition from contemporary scientists such as Friedrich von Müller and Paul Ehrlich, as well as honorary degrees from several universities. However, although nominated several times for the Nobel Prize, he was never a recipient.

Noguchi has also been credited with producing an effective antiserum against Rocky Mountain spotted fever, and lauded for his research showing Bartonella bacilliformis to be the same causative agent in both Oroya fever and verruga peruviana.

A DARK SIDE Although Noguchi's work with T. pallidum represented his most important scientific contribution, he also

${ }^{1}$ Emeritus Professor of Medicine, University of Hawaii, Honolulu, USA, ${ }^{2}$ Research carried out during fourth year medical student elective, John A Burns School of Medicine, University of Hawaii, Honolulu, USA

Correspondence: Prof Tan Siang Yong, 2230 Liliha Street, Suite 104, Honolulu, HI 96817, USA. siang@hawaii.edu 
tackled other infectious conditions such as poliomyelitis, rabies, herpes, yellow fever and trachoma. However, none of these projects met with the same success. His initial identification of the aetiologies of poliomyelitis, trachoma, rabies, and yellow fever all proved incorrect. Of particular disappointment was his work on yellow fever. During an expedition to Ecuador in 1918, Noguchi discovered the spirochaete, Leptospira icteroides (L. icteroides), in a small percentage of patients who had been diagnosed with yellow fever. Subsequent experiments with guinea pigs, unfortunately with inadequate controls, led him to conclude that yellow fever was caused by L. icteroides. Notwithstanding the Ecuadorian government honouring him for his contributions to public health, researchers soon began to publish findings that refuted Noguchi's claim, earning him harsh criticism over his methodology, poor keeping of records, overconfidence and haste. Yellow fever was later shown to be a viral illness, and Noguchi may have confused the condition with leptospirosis.

Noguchi's work became increasingly erratic and inaccurate. Many of his findings were not reproducible, including his claim of being able to culture the syphilis spirochaete. He was also accused of undertaking unethical human experiments such as the inoculation of leutin, an extract of syphilis, into the skin of normal children. Noguchi himself had contracted syphilis, which may have progressed to neurosyphilis, which may explain his subsequent secretiveness and paranoia. He became careless, even reckless, in the laboratory, exposing himself and his coworkers to dangerous pathogens.

DEATH AT 52 Noguchi was one of the first Japanese scientists to ever gain worldwide renown. Although American and European scholars frequently travelled internationally to study or share their work, few Japanese scientists lived or worked outside of Japan before the twentieth century. Among the handful of his Japanese contemporaries who did gain international recognition were Takaki Kanehiro, who discovered a link between a nutritional deficiency and beriberi; Umetaro Suzuki, who discovered thiamine, the cure for beriberi; and Nagai Nagayoshi, who discovered ephedrine in 1885 and went on to synthesise methamphetamine in 1893.

In 1927, Noguchi travelled to Accra (now Ghana) as part of an expedition organised by the Rockefeller Foundation. The following year, he contracted yellow fever, probably from careless exposure in the laboratory, and died on May 21, 1928. His body was returned to the United States, where he was buried with honours in the Woodlawn Cemetery in the Bronx, New York, United States. The Japanese government awarded Noguchi the prestigious Order of the Rising Sun, Gold and Silver Star - the second highest class of the award - and eventually, his portrait found its way onto a 1,000 Japanese yen banknote. With his death, Noguchi's childhood home in Inawashiro became a museum, with the world having lost a "man of humanity" and a "martyr of science".

\section{BIBLIOGRAPHY}

- Clark PF. Hideyo Noguchi, 1876-1928. Bull Hist Med 1959; 33:1-20.

- Eckstein G. Noguchi. New York: Harper \& Brothers, 1931.

- Flexner S. Hideyo Noguchi. Science 1929; 69:653-60.

- Hideyo Noguchi Memorial Museum. The Chronological History of Hideyo Noguchi [online]. Available at: www.town.inawashiro.fukushima.jp/eng/ main_eng_noguchi.html. Accessed November 24, 2008.

- Kita A. Dr Noguchi's journey: a life of medical search and discovery. New York: Kodansha International, 2005.

- Plesset IR. Noguchi and his patrons. Rutherford: Fairleigh Dickinson University Press, 1980.

- Smith T. Memorial Addresses: Hideyo Noguchi. Bull N Y Acad Med 1929; 5:877-86.

- Takahashi A. The Death of Hideyo Noguchi and the Rockefeller Institute for Medical Research. In: Research Reports from the Rockefeller Archive Center. New York: Rockefeller Archive Center, 2000: 17-19. 